\title{
LA DESINTEGRACIÓN FAMILIAR Y EL APRENDIZAJE EN NIÑAS Y NIÑOS DE IV GRADO ${ }^{8}$
}

\author{
Maria Estela Vargas Tess ${ }^{9}$ \\ Nalia Rosales Cunningham ${ }^{10}$ \\ Argentina García Solórzano ${ }^{11}$
}

\begin{abstract}
RESUMEN

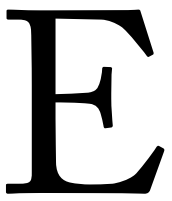
sta investigación se hizo para contribuir a una adecuada atención educativa en el proceso de aprendizaje de la niñez del Cuarto Grado en la Escuela Irma Cajina Paiva, del barrio El Cocal, en la ciudad de Bilwi del municipio de Puerto Cabezas, en la Región
\end{abstract} Autónoma del Atlántico Norte-RAAN, en el año 2006. Las niñas y niños proceden de familias desintegradas y el objeto es comprender los efectos negativos de la desintegración familiar en los procesos educativos de la niñez.

La desintegración familiar provoca a niñas y niños problemas psicológicos de orden emocional y afectivo, que afectan su desempeño en el proceso de enseñanza- aprendizaje: baja autoestima, repiten grados académicos, bajo rendimiento, deserción escolar, alteraciones de la conducta social, problemas de aprendizaje y se afecta las relaciones interpersonales dentro y fuera del aula de clase. Situaciones que afectan más a niñas que a niños; sin embargo, en ambos casos hay riesgos de maltrato y abuso infantil, no respetan límites y los derechos de la niñez, lo que ocasiona vagancia, drogadicción, delincuencia, huída temprana del hogar, entre otros.

Este problema tiende a aumentar y no está siendo atendido en la escuela ni en el hogar, por lo que recomendamos al Ministerio de Educación y a la Dirección de la Escuela, implementen estrategias eficaces para la sensibilización e integración efectiva de padres y madres en la educación de niñas/os y jóvenes. Igualmente, una

8 Investigación realizada por URACCAN Recinto Bilwi.

9 Licda. Maria Estela Vargas Tess. Licenciada en Ciencias de la Educación con mención en Geografía email: evargas_70@hotmail.com

10 Licda. Nalia Rosales Cunningham. Licenciada en Ciencias de la Educación con mención en Geografía

11 MSc. Argentina García Solórzano. Master in Arts. Secretaria Académica. URACCAN Bilwi. Tutora de la investigación. 
campaña de sensibilización permanente para la toma de decisión madura a la hora de constituir familias estables que brinden afecto, amor, seguridad, estabilidad y una educación integral a niñas/os y jóvenes. Y, a los docentes, capacitación continúa sobre el manejo de niñas y niños en riesgos psicológicos y emocionales, paciencia, comprensión y afecto sobre todo para la niñez carente de afecto en sus hogares y especialmente para los que proceden de hogares desintegrados.

\section{INTRODUCCIÓN}

Hay muchos hogares en Bilwi, RAAN, Nicaragua, en los cuales solamente está la mamá y/o la abuela. Hay familias de padres divorciados, separados, que forman otra familia y queda la niñez abandonada por la desintegración familiar, causando mucho daño, manifestándose en problemas de diferente orden. Podría considerarse que es un comportamiento que cada vez más se va generalizando, y provoca muchas veces el abandono del hogar, sus estudios, y que se incline por la vagancia, buscando comprensión en la calle, con grandes riesgos de convertirse en un antisocial.

"Según el Fondo Nicaragüense para la Infancia (FONIF), ahora Ministerio de la Familia, la institución contabilizó solamente en Bilwi, Puerto Cabezas, un total de 353 niñas/os y adolescentes, trabajando en las calles, de los cuales, 245 eran varones (69.4\%) y 108 del sexo femenino (30.6\%).” (Navarrete C. Alfonso, 2000.)

Como maestras abordamos esta problemática por considerarla un factor negativo que afecta en gran manera la personalidad y el proceso enseñanza- aprendizaje de niñas y niños. Esa situación aumenta el fracaso escolar, la deserción, alteraciones en la conducta en la escuela y afectaciones generales en la personalidad de la niñez y adolescencia..

Los resultados de este trabajo tienen que ver con la relación familia-escuela, la responsabilidad de padres y madres, la responsabilidad de docentes, directores y comunidad en la implementación de estrategias para abordar las consecuencias de la desintegración familiar. Algunas recomendaciones que se consideran pertinentes para el Ministerio de Educación, directores, docentes, padres y madres de familia.

\section{REVISIÓN DE LITERATURA}

Se presentan conceptos que explican algunas situaciones y factores que afectan el proceso enseñanza - aprendizaje: la familia, importancia de la familia, desintegración familiar, consecuencias de la desintegración familiar, proceso enseñanza - aprendizaje, rendimiento académico, relaciones familia- escuela, escuela - familia. 


\section{LA FAMilia}

Para Ellsberg, et, al. (1996), "la familia es una red extensa, flexible y múltiple en el centro de la vida de las personas (...) la estructura familiar afecta de modo significativo al desarrollo académico y social de los hijos, que es tres veces menos probable que los niños o niñas de tres a cuatro años que crecen con su padre y madre, experimenten problemas emocionales de difícil atención". En tal sentido para atender de forma integral a la familia, especialmente la niñez y los jóvenes, en la Costa Caribe, el Sistema Educativo Autonómico Regional -SEAR-, (2000) plantea como uno de sus fundamentos: "la familia como base del proceso de formación de las personas, en coordinación con la comunidad y el Estado, promoviendo la erradicación de la violencia contra mujeres, niñas, niños, las y los adolescentes.

Según Gómez C. Ángel y Núñez R. Olga L. (2004), es en ella (la familia) precisamente, donde se expresa por excelencia el carácter interactivo del desarrollo planteado. Para Navarrete C. Alfonso, (2000) "La familia es el principal referente de los seres humanos, la cual va más allá de los cuidados y apoyos que se le han asignado tradicionalmente; es en el seno de este núcleo de la sociedad donde se sientan las bases para la formación de la identidad del ser humano, la autoconciencia, la conexión al pasado, y la esperanza en el futuro."

\section{Importancia de la familia para la juventud del Atlántico Norte}

Navarrete C. Alfonso, (2000), plantea que la familia es el primer y el más importante punto de referencia para los niños y las niñas; la familia pone todo lo necesario para la supervivencia: elementos físicos y materiales como la comida, el hogar, la protección física y juguetes; elementos psicológicos como el amor, demostración de protección, estima, interés, comprensión; y elementos espirituales e ideales como la forma de pensar, respeto a los demás, sanidad espiritual, religiosidad, solidaridad y sensibilidad humana.

\section{Qué es la Desintegración Familiar}

Suárez Rodolfo (2005), sostiene que la desintegración familiar es donde queda incluido no sólo que los padres estén divorciados, sino que viviendo bajo el mismo techo, se encuentren en conflicto constante y no compartan las mismas metas, y donde no se cumplen con las funciones primordiales de la familia que son alimentación, cuidado, afecto, socialización, educación, y donde se delega el cumplimiento de las anteriores funciones, en personas como los abuelitos, los hermanos mayores, algún familiar e inclusive a personas ajenas a la familia. Por otro lado, Máximo Rugama Castillo,(2000) afirma que la desintegración como núcleo específico de algunos hogares, que en la mayoría de los casos 
cometen los padres, hacia sus esposas e hijas/os menores, son entre otros factores, los generadores de los problemas de conductas en la niñez y adolescencia.

\section{EFECTOS DE LA DESINTEgRACión FAMILIAR}

Es importante señalar lo que plantea el Dr. Edel N. Rubén (2004), que expresa que por estas inseguridades que la familia desintegrada ha sembrado en la mentalidad del niño, este demuestra desinterés en sus estudios, su nivel de aprendizaje es lento y presenta muchas dificultades en su período de estudio, ya que no pone atención en las explicaciones que brindan los docentes en el aula de clase, y el trauma de este momento le perseguirá en todo el ámbito de su convivencia diaria. Y Navarrete C. Alfonso, 2000, plantea que como consecuencia de la desintegración familiar se dan los siguientes efectos: distorsionamiento de la conducta y la personalidad de los niños y los adolescentes; incomprensión y desentendimiento entre los miembros de la familia; inducción de los jóvenes a las drogas y el alcoholismo; incremento de la prostitución infantil y adolescente; aumento del número de madres solteras y jefas de hogares; y estancamiento absoluto del progreso de vida de todos los miembros de la familia.

Similar percepción tiene Marquardt, E. (2006) para explicar algunos patrones de comportamiento negativos más evidentes en los niños de familia dividida: inasistencia, retraso escolar y problemas psicológicos. En ese sentido Booth, (2001) agrega que con esos tipos de problemas dentro de una familia, siempre hay efectos negativos en el aprendizaje de los niños durante la edad escolar, tanto emocional y psicológico y por ende, un rendimiento académico bajo y muy pocas veces el padre asume la responsabilidad de sus hijos.

\section{Proceso de enseńanza - aprendizaje}

Según Solá, M. J. (1998) el proceso de enseñanza - aprendizaje es el conjunto de pasos sistemáticamente ordenados que tiene como propósito brindar los instrumentos teóricos - prácticos que le permitan al ser humano desarrollar y perfeccionar hábitos, actitudes, aptitudes y conocimientos que se apliquen en el desempeño eficiente en sus actividades diarias. En este proceso, para la Dra. Ibarra Mustelier (2003), la educación es demasiado importante para dejarla sólo en manos de los maestros, por lo que los padres debemos ser agentes más activos ante el proceso educativo de nuestros hijos. Comprender que la dinámica educativa nos incluye a todos, es una actividad permanente que integra a los hijos, a los maestros, a los padres y a la comunidad en su conjunto.

Pérez Gómez (1992), sostiene que es necesario conocer las condiciones en las que se encuentra el individuo que aprende, es decir, su nivel de captación, de madurez y de cultura, entre otros. A esto, agregamos lo que el Dr. Juan Bautista Arríen afirma: "nume- 
rosos e importantes estudios han señalado la relación entre escolaridad de los padres y de la madre en particular y factores que afectan la salud, la educación y el desarrollo de los hijos", lo que confirma la relación entre escolarización y los factores de desarrollo de un país. Es importante considerar este aspecto debido a que las madres son las que pasan más tiempo en casa y atienden más a las hijas e hijos.

\section{Qué tiene QUe ver la Familia con la Escuela}

Destacamos lo planteado por la Dra. Ibarra L., (2003) sobre la relación de la escuela con la familia y viceversa. Expresa que en la actualidad, las familias, se encuentran muy afectadas por influencias sociales negativas propias de la sociedad, siendo más débiles en su estructura, encontrándose inmersas, en muchos casos, en problemas reales que afectan a su estabilidad. Ahora veamos según Martínez Ana, et al. (2005), las demandas de la escuela a la familia y viceversa y algunas recomendaciones para mejorar esa relación. Afirma que la escuela demanda apoyo en exigencias cotidianas, la escuela busca que la familia garantice el cumplimiento de aspectos formales: adecuada presentación personal, asistencia y puntualidad, cumplimiento con los útiles y cuotas, asistencia a reuniones de apoderados y citaciones personales, entre otros. Ellsberg, et, al., (1996), sostienen que en general los niños que viven con papá y mamá tienen menos problemas de comportamiento, en comparación con los niños cuyos padres están viviendo juntos pero no están casados.

De esta situación también se ocupa el Plan Nacional de Educación, (2000), al plantear que "deben abordarse no sólo los factores a lo interno del centro educativo que afectan el aprovechamiento y provocan el abandono, sino también implementar estrategias que garanticen las transferencias e intervenciones necesarias en el ámbito familiar y comunal para que sea posible la realización de la inversión en la educación de los más pobres." Asimismo, el principio No. 9 del Plan Nacional de Educación deja claro que: "Es deber y derecho de madres y padres de familia, instituciones, organizaciones y demás integrantes de la Sociedad Civil, participar activamente en la planificación, gestión y evaluación del proceso educativo, dentro de la realidad nacional, pluricultural y multiétnica.”

\section{MATERIALES Y MÉTODOS}

Se seleccionó el cuarto grado de la escuela Irma Cajina Paiva debido a que en indagaciones previas se conoció que había mayor cantidad de niñas/os con problemas en relación al tema seleccionado. El estudio es de orden cualitativo - descriptivo, con un universo de 30 estudiantes del cuarto grado procedentes de familias desintegradas o de hogares que aunque tengan padres, por razones de trabajo se mantienen fuera de la localidad, nunca están en el hogar que es otra forma de abandono. Se seleccionaron por conveniencia una 
muestra correspondiente a 15 alumnos ( 9 mujeres y 6 varones) que representa al $50 \%$ del universo.

\section{MÉTodos Y TÉCNICAS UTILIZADAS}

Previo a la entrevista, a las fuentes se les dio a conocer los objetivos del estudio y el por qué se seleccionaron, destacando la importancia que tiene la información que nos pudieran brindar, a lo que gustosamente accedieron, así en un ambiente cordial y de confianza se realizaron las entrevistas individuales y de grupo focal, en lengua miskita, por ser la lengua materna de las fuentes. Asimismo se realizaron observaciones en el aula de clases y la revisión documental en la escuela.

Una vez obtenidos los datos se ordenaron y clasificaron por objetivo y por fuente. Su procesamiento se realizó utilizando el procedimiento del palote y posteriormente la categorización y análisis conforme objetivos propuestos. Se ordenaron las respuestas por preguntas, y dado que había algunas de ellas comunes, se ordenaron y clasificaron los resultados de cada fuente para proceder al análisis e interpretación, triangulando la información, lo que permitió llegar a conclusiones por objetivos, reflexionar y plantear algunas recomendaciones.

\section{Aspecto Ético}

Se aseguró a las y los informantes claves que los datos obtenidos no serán utilizados para fines lucrativos y que se utilizarán únicamente con el propósito de contribuir a superar las barreras que afectan el proceso enseñanza-aprendizaje y se aseguró la preservación del anonimato de las personas que brindaron información para la realización del estudio y el retorno de la información.

\section{RESULTADOS Y DISCUSIÓN}

En el estudio, de acuerdo al contexto se maneja como familia desintegrada aquella en que la ruptura del matrimonio o pareja, se desentiende de los hijos e hijas, creciendo estos al lado de madrastras o padrastros; o bien, solamente con uno de los padres, siendo normalmente la madre la que asume toda la responsabilidad del hogar, a veces con apoyo de las abuelas u otros parientes de las niñas y niños.

El estudio demuestra que un $100 \%$ de las niñas y niños viven con un solo miembro de su familia, ya sea madre, abuela, tía y padrino/madrina. La mayoría de ellos son repitentes y la edad oscila entre diez a quince años. Eso puede significar riesgos para esa niñez, afectando su vida escolar, familiar y entorno sociocultural. Las causas de la desintegración 
familiar son diferentes en niñas y niños, en ambos casos hay riesgos de abuso, prostitución, vagancia, drogadicción, delincuencia, abandono temprano del hogar.

Las nińas normalmente tienen menos tiempo para hacer las tareas, asumen más responsabilidades con los trabajos del hogar, ejemplo: lavar ropa, trastes, cocinar cuidar sus hermanos pequeños y otros; tienen más deberes que derechos, son más sumisas y reprimidas, sirven a los hermanos, reciben más maltrato. En cambio los niños tienen más libertad o más bien, libertinaje, asumen menos responsabilidad con los trabajos de la casa, tienen más derechos que deberes, son servidos por las hermanas, son menos sumisos, más desobedientes y rebeldes.

\section{INCIDENCIA DE LA FAMILIA DESINTEGRADA EN LA ASISTENCIA A LA ESCUELA Y EN EL RENDIMIENTO ACADÉMICO}

El director, la maestra y casi todas las madres entrevistadas expresaron que la mayoría de las/os alumnas/os no asisten diariamente a la escuela porque deben apoyar a la familia con los trabajos domésticos de la casa ya que las madres trabajan y humanamente no pueden con todo el qué hacer, hasta pareciera que no tienen más alternativa que la de depositar parte de la carga del hogar en sus hijos e hijas. Agregan que a veces esa situación provoca retiro de la escuela, repitencia entre otras cosas.

Si el padre ya no está en el hogar y como generalmente la madre debe buscar como subsistir en trabajos fuera de casa, las nińas y niños a temprana edad tienen que ocuparse de la casa. Se pudo verificar que la mayoría de esta niñez pasan en el día sin la presencia ni supervisión de adultos/as, y deben asumir el rol de responsables del hogar. Al respecto, expresa Navarrete C. Alfonso, 2000 que el Ministerio de la Familia, contabilizó solamente en Bilwi, Puerto Cabezas, un total de 353 niños y adolescentes de ambos sexos, trabajando en las calles, de los cuales, 245 eran varones (69.4\%) y 108 del sexo femenino (30.6\%)."

La mayoría de las madres de familia y alumnas/os entrevistadas/os expresaron que van muy bien en clases, unas aceptaron que tienen dificultades en el aprendizaje o bajo rendimiento académico por el hecho de que sus hijas e hijos no asisten diariamente a clases; esto evidencia el poco interés y responsabilidad en la formación educativa de ellos; esto dentro del contexto general refleja la repetición de patrones de crianza que se repiten en sucesivas generaciones, como parte de la baja autovaloración en relación de la elección de parejas, asimismo el sistema que en sus valores educativos no se ha preocupado por un fenómeno recurrente, el hecho dramático incide contra toda la humanidad de esta nińez y jóvenes, violando los Derechos Humanos en toda su integridad; al ser el futuro de la sociedad, esa niñez y jóvenes, el problema es más grave por cuanto no habrá ningunas expectativas del desarrollo humano, por cuanto la educación es la cantera de todo desarrollo integral en las sociedades. 
El sistema educativo y la sociedad en general tiene corresponsabilidad en esta desvirtuación de la comprensión de lo que es la vida y el desarrollo de una cultura con equidad, en ambientes sanos y posibilitadotes; engranaje que se vincula con la parte psicológica en el tratamiento de estos casos, el sistema jurídico porque las herramientas no se aplican, sobre todo cuando de la defensa de estos justos derechos de la nińez y la juventud se tratan.

En el sistema educativo esto viene desde las raíces que es el criterio filosófico y humano con las formas de afrontar esta situación por parte del Estado; enfoques y criterios curriculares, apropiación de psicologías y metodologías por parte de los docentes en talleres y simposios de actualización, seguimiento y sistemas de evaluación para evaluar estas competencias en las formas con qué se interactúa con estos estudiantes, el criterio que se tiene para la participación de la comunidad en la escuela y de la escuela para la comunidad la cual está divorciada del entorno sociocultural, la escuela no está vinculada para la vida y por lo tanto no se apropia de las posibilidades creativas de ese medio social, ni le corresponde con sus expectativas, necesidades e intereses, ni resulta grata ni motivadora un tipo de educación tradicional donde los estudiantes sólo reproducen, repiten y no crean en un proceso dinámico, dialógico y participativo.

Este engranaje tiene que ver con los enfoques y realidades que se viven en las Escuelas Normales tradicionales, donde los profesores son los poseedores del saber, saben distinguir entre los modelos o paradigmas de la educación tradicional de una educación liberadora y participativa, pero ellos mismos no aplican estos métodos y estas concepciones

Esta investigación de caso tiene importancia a nivel educativo nacional, porque por su situación generalizada refleja una crisis nacional y como toda crisis psicosocial debe verse como la falta de una visión y de una estrategia de soluciones a la problemática. En este caso, a pesar de que las madres y estudiantes expresaron que van muy bien en clase, se pudo comprobar a través del registro diario de la docente que las/os alumnas/os tienen mucha dificultad tanto en la asistencia diaria como en su rendimiento académico.

Se pudo constatar que hay $68 \%$ de inasistencia, $32 \%$ de asistencia al mes y el rendimiento académico en el mes de Octubre 80\% reprobado, 20\% aprobado, en el mes de Noviembre $79 \%$ reprobado y $21 \%$ aprobado. Se sabe que pueden haber diferentes causas para que haya bajo rendimiento académico y ausentismo a clases, pero la desintegración de la familia incide mucho en esta situación encontrada. Esto tiene que ver con lo que plantea el Dr. Edel N., Rubén, (2004), quien explica que las inseguridades que la familia desintegrada provoca en las niñas y niños trae como consecuencia desinterés por el estudio, su nivel de aprendizaje es lento y presentan muchas dificultades en el aprendizaje, ya que no ponen atención a las explicaciones que brindan los docentes en el aula de clase.

En síntesis podría decirse que las niñas, niños y madres entrevistadas no toman con seriedad la afectación al proceso de enseñanza aprendizaje. Sentimos que en sus respuestas 
ni las niñas, niños y madres, no relacionan las ausencias, la falta de apoyo en el hogar con el bajo rendimiento académico, que tampoco es considerado como tal, pues manifiestan que "van bien en clases". En cambio para la maestra y el director es notoria la afectación de las niñas y niños en la escuela.

\section{APOYO DE LOS PADRES Y MADRES DE FAMILIA A SUS HIJOS CON LA TAREA ESCOLAR}

La maestra, algunas madres y las/los niñas/os en su mayoría coinciden en expresar que no reciben la ayuda que necesitan, porque sus madres pasan trabajando y otras están en la casa pero no demuestran interés en apoyar a sus hijos e hijas en la escuela, pudiera ser este el motivo que las niñas y niños van al aula de clase sin realizar las tareas asignadas en las diferentes asignaturas, lo cierto es que en el hogar no hay armonía, el agobio por la sobrevivencia de estas madres de familia, la falta de educación que ellas mismas han recibido, se transporta en la ausencia de un acercamiento humano y comprensivo, apoyo y seguimiento hacia el cumplimiento de las tareas escolares.

A través de las visitas directas al aula de clase se detectó que la mayoría de los alumnos, procedentes de una familia desintegrada no reciben el apoyo necesario de parte de sus padres, porque van a clase sin realizar las tareas que llevan a su casa. Así lo explica Ellsberg, et, al .,(1996), al plantear que "la estructura familiar afecta de modo significativo al desarrollo académico y social de los hijos." De aquí podemos deducir la importancia del apoyo de la familia en el proceso enseńanza aprendizaje. En ese sentido Boorth, A.(2001), afirma que cuando se da este tipo de problemas dentro de una familia, siempre hay efectos negativos en el aprendizaje de los niños durante la edad escolar, tanto emocional y psicológico y muy categóricamente ańade, se da un rendimiento académico bajo de sus hijos y muy pocas veces asume el padre la responsabilidad de sus hijos.

Algunas niñas/os entrevistadas/os dijeron que su mamá no les puede ayudar, porque no entienden las tareas. Aunque no se indagó sobre el nivel académico de las madres, varias de ellas lo mencionaron, parece ser un dato importante ya que son ellas quienes a pesar de su trabajo fuera de casa están más cerca de las niñas/niños.

\section{INTERRELACIÓN DOCENTE, ESTUDIANTE Y PADRES DE FAMILIA}

De acuerdo al análisis realizado en este estudio, se puede afirmar que la relación entre maestra/o, madres e hijas/hijos no es la más adecuada porque las madres muy pocas veces visitan a la maestra y tampoco se presentan a reuniones convocadas por la Dirección, o llegan en horas no indicadas. Se puede decir entonces que entre niñas y niños, maestra y madres no existe buena comunicación sobre el desempeńo, comportamiento y logros de niñas y niños. Y si no está informada la madre de cómo van sus hijas/hijos, no podría ayudarles. 
La interrelación entre madres e hijas/os no es la mejor. A veces se dan situaciones en que las madres le dan la autoridad al padrastro, éste al recibir quejas lo que hace es maltratar físicamente al niño o niña, a quien "educan a su manera". Si bien no se entrevistó a padres ni padrastros, estando en la escuela se pudo conversar con uno de ellos, y nos manifestó que "a los hijos hay que educarlos a como nos educaron a nosotros". Se puede pensar que esta es una forma de justificar la violencia en contra de las niños y niños. Según las y los alumnas/os entrevistados/as, la mayor parte de ellos y ellas viven en un ambiente desagradable. Se supone que debido a esta situación que enfrenta la familia, la relación entre maestra y madres de familia se ve seriamente afectada ya que los padres/madres no asumen sus responsabilidades con la educación de sus hijos.

$\mathrm{Al}$ respecto, de acuerdo a los resultados obtenidos, la escuela no ha buscado alternativas de solución. Aunque en las reuniones con padres y madres de familia abordan diferentes situaciones, y plantean la importancia del ambiente del hogar, aparentemente no hay cambios, y debido a la poca asistencia a esas reuniones por parte de las madres y/o padres, no les llegan esos mensajes. Se puede afirmar entonces que los padres no cumplen con sus roles, sobre todo si han formado otra familia. Esto perjudica especialmente a los alumnos en su proceso de aprendizaje.

Se pudo verificar que la relación entre alumnas/os y la maestra es excelente. Las niñas/os en un 100\% dijeron que la maestra es comprensiva, que los atiende con amabilidad, pero que su problema es en casa, ya que se sienten solos y no le ponen mente a las clases, porque ni su papá ni su mamá les ayudan y pudiera ser que por eso mismo estas niñas y niños tampoco le dan importancia a los estudios, pues no tienen la motivación que ese proceso necesita. Al respecto, la Dra. Ibarra L., (2003) sostiene que hay que comprender que la dinámica educativa nos incluye a todos, es una actividad permanente que integra a los hijos, a los maestros, a los padres y a la comunidad en su conjunto, es por lo tanto importante recordar que el proceso enseñanza aprendizaje requiere del apoyo de la familia.

Asimismo plantea algunas recomendaciones para mejorar esa relación. Estas recomendaciones podrían retomarse y readecuarse en un contexto como el de nuestra región: multicultural, multilingüe, en el que contamos con un modelo educativo autonómico regional que demanda la participación de padres y madres, que vela por los derechos de niñas y niños, por la erradicación de la violencia intrafamiliar, y que además cuenta con un marco legal que soporta la aplicación de la educación intercultural bilingüe.

Algunas de las estrategias que recomienda son espacios de reflexión-acción de docentes y directivos, acercamiento en los espacios habituales, generar un clima de mayor horizontalidad y calidez, participación de los padres al interior de la sala de clases, abrir espacio para que los padres comuniquen sus saberes a los nińos, espacios informativos y formativos, cultivar áreas de interés de los padres. En la actualidad, según la Dirección de la Escuela Irma Cajina Paiva en las reuniones dan espacios para 
la reflexión, solicitan el apoyo a los padres/madres de familia con los trabajos escolares asignados siendo una ventaja que la enseńanza es bilingüe y pueden aportar sus conocimientos en la enseñanza de sus hijos. Sin embargo no hay respuestas positivas al respecto por el poco acercamiento de la familia a la escuela.

\section{Relación Dirección-Padre / Madre de familia}

La Dirección del centro expresa de que entre ellos y padres/madres de familia tienen muy buena relación, ya que integran diferentes comisiones escolares, pero en porcentaje muy reducido para resolver diferentes problemas que se presentan en el centro, estos padres siempre nos visitan y nos, brindan ayuda en lo que ellos pueden; no nos sentimos tan solos como en los años anteriores expreso la dirección, hay mayor cooperación, coordinación para resolver los problemas educativos.

En algunos casos de indisciplina seria o de mal rendimiento académico, se manda a llamar directamente con una nota al papá o a la mamá de la niña o niño. Algunos se presentan en la fecha indicada, pero en otros casos llegan cuando quieren o no llegan. No se sabe si es por falta de tiempo o por irresponsabilidad, en todo caso no afectamos de ninguna manera el/la estudiante. "Los padres/madres de familia tienen que brindar confianza y visitar la escuela" expresó el director para que haya mayor relación entre la maestra y padres/madres de familia, además expresó que "la visita constante de padres de familia ayuda tanto a la dirección como al maestro, a ser muy responsable de su trabajo y no ausentarse del mismo."

\section{RESPONSABILIDAD DE LOS PADRES/MADRES}

Algo sustancial para apoyar a niñas y niños es el grado de responsabilidad de padres y madres. Según los alumnos y la maestra expresaron que los padres de familia no asumen sus responsabilidades a como se debe. Que no asisten a las reuniones cuando la dirección los convoca, no visitan a la maestra para preguntar cómo van sus hijos y que no los apoyan con las tareas que llevan a la casa, y según algunos de los niños, que más bien si les piden ayuda se enojan y les gritan, diciendo que no tienen tiempo, o que se sienten cansados de la jornada de trabajo. Al respecto algunas de las madres entrevistadas decían que sus ocupaciones no les permitían ayudar a sus hijas/os, otras dijeron que no saben lo que sus hijos tienen qué hacer y no saben cómo ayudarles, y que tampoco van a la escuela a ver cómo van sus hijos, porque no les queda tiempo.

Además se encontró madres que expresaron que ellas no tienen ninguna responsabilidad con la escuela. No visitan la escuela para nada ni asisten a las reuniones convocadas por la dirección de la escuela, estas madres de familias tampoco ayudan con la tareas de sus hijos ni les dan tiempo a sus hijos/as para hacer sus tareas, ni estudiar. Según ellas 
mismas, sus hijas también tienen mucho que hacer en sus casas, por eso (sostiene una de ellas) "yo sé que va mal en sus estudios, pero no puedo hacer nada al respecto." La anterior actitud se contrapone con lo expresado por la Dra. Ibarra M. 2003, que plantea que "la educación es demasiado importante para dejarla sólo en manos de los maestros. Por lo que los padres debemos ser agentes más activos ante el proceso educativo de nuestros hijos."

Asimismo afirma que la escuela requiere de los padres/madres, apoyo en exigencias cotidianas, que la familia garantice el cumplimiento de aspectos formales como por ejemplo la adecuada presentación personal, asistencia y puntualidad, cumplimiento con los útiles y cuotas, asistencia a reuniones de apoderados y citaciones personales, entre otros, y sobre todo apoyo en el trabajo escolar diario para garantizar el refuerzo en los contenidos trabajados en clase, proveer a los niños de múltiples materiales de consulta, cumplir con las tareas, fomento de hábitos de estudio.

\section{Comportamiento DE LOS/LAS ALUMNOS/AS EN EL AULA DE CLASE}

Las y los alumnas/os, la maestra y el director tienen puntos de vista diferentes con relación al aprovechamiento escolar y el comportamiento en la escuela. Se pudo constatar en los recreos o a la salida de clases, algunos de estos niñas/os manifiestan formas violentas en sus juegos (patadas, tiran objetos, juegos de manos, muchas malas palabras, pelean). En el aula esta situación es menos frecuente. No se observó casos extremos de violencia. La maestra sostiene que hace lo que puede con los niños que tienen dificultades en el hogar. Que sus alumnos son inquietos, que quieren hacer lo que quieren, salen del aula de clase sin permiso, molestan a sus compañeros, si la maestra les llama la atención no les gusta, se enojan. A veces no sabe qué hacer.

Coincide lo anterior con lo expresado por el director, y afirma que las niñas y niños de las familias incompletas o desintegradas se comportan mal, son inquietos, no se pueden controlar, se corren en hora de recreo, presentan inasistencia, no cumplen con las tareas y trabajos, su proceso de aprendizaje es lento, su rendimiento académico es bajo, pelean y se defienden a como sea. Se nota en el aula de clase algunos signos de inseguridad en los trabajos que hacen, no les gusta presentar lo que hacen a la maestra, no les gusta opinar en clase, quizás porque creen que está mal hecho el trabajo o que no van a decir lo que espera la maestra. También se percibe la baja autoestima, podría ser que se comparan con sus compañeras/os y se creen menos que las/los demás, o pudiera ser que se sienten rechazados porque reflejan lo que les ocurre en el hogar.

Además, se encontró algunas manifestaciones de desconfianza, no demuestran confianza en sí mismos ni en los demás, pareciera que siempre están a la defensiva. Hay casos de aislamiento, se pudo observar que algunas/os, sobre todo las niñas se aíslan del grupo, no participan en trabajos grupales y que hay inestabilidad, pues una familia desintegrada 
no es estable, por lo general viven alquilando casas, a veces están obligados a cambiar de casas, escuela y familia. Pareciera que siempre están esperando alguna sorpresa desagradable. Es evidente que esta niñez manifiestan conductas relacionadas con una autoestima muy baja.

Demuestran poco afecto, poco amor, carińo como otras niñas/os que abrazan, saludan y hasta besan a la maestra, tal parece que les cuesta expresar sus sentimientos y emociones. Esto se complementa con algunas frases dichas por los estudiantes entrevistados, al consultarles sobre lo que les gustaría cambiar en su familia, contestó uno de ellos: "el comportamiento de sus padrastro y tíos, ya que llegan borrachos en la casa y hacen escándalo". Algunas de las madres expresaron que sus hijos no juegan ni en la casa mucho menos en la escuela, "ya que el padrastro siempre está vigilando" pero esa vigilancia se vuelve a veces en persecución. Las expresiones anteriores por parte de los estudiantes, podrían ser indicios de que la parte afectiva en los hogares no anda bien.

En cuanto a su propio comportamiento, las y los alumnas/os consideran que ellos se portan bien y que van bien en clases, que su maestra es una persona comprensiva y que les ayuda en lo que puede. A través de observaciones directas en el aula de clase se detectó que los alumnos de cuarto grado de la Escuela Irma Cajina Paiva tienen alteraciones en la conductas y las mismas son manifestadas en el aula de clase, algunos alumnos son distraídos, inquietos, desobedientes, lo cual demuestra que los mismos necesitan de un apoyo sistemático en el reforzamiento positivo de la conducta. Esto reafirma lo que expresaron tanto el director como la maestra. Esta situación la explica muy bien Martínez, Ana ,et. al.(2005), quienes afirman que las principales reacciones de los hijos ante familias conflictivas, se circunscriben en torno a tres ejes que son: el psicológico y físico, las relaciones sociales que conlleva entre otras cosas la agresión, consumo de drogas, depresión, ansiedad, retraimiento social, y problemas académicos.

Esta idea es reforzada por Marquardt, E. (2006), que destaca además que estas niñas y niños viven altos niveles de estrés, depresión, ansiedad y baja autoestima durante sus ańos de adolescencia, problemas que puede reducir su capacidad de concentrarse en la escuela. Se puede afirmar que sí hay problemas de orden Psicológicos, emociónales y afectivos que afectan el comportamiento en el aula de clase por parte de niños y nińas de familias desintegradas.

\section{El Aprendizaje}

Según la maestra y el director "el proceso enseñanza aprendizaje de estos alumnos es lento debido al problema de desintegración familiar que enfrentan". Lo dicho por la docente y el director no significa que la desintegración familiar sea la única causa de bajo nivel de aprendizaje pero sí, es un factor decisivo en la formación de niñas(os). Consideran que eso les genera en su aprendizaje una asimilación lenta y que por esa razón existen estu- 
diantes con bajas calificaciones, reprobados y hasta repitentes, algunos de ellos deberían estar en grados superiores, ya que sus edades oscilan entre diez hasta quince años.

Se pudo comprobar que una familia desintegrada trae consecuencias negativas tanto en el aprendizaje de los niños como en su conducta. Muchos de estos niños no asisten diariamente a la escuela, ya que la madre asume la responsabilidad de todo el hogar, y la mayor parte de su tiempo se dedican al trabajo fuera del mismo, por lo que no le da tiempo de visitar la escuela, platicar sobre los problemas de los hijos, ni ayudar en las tareas diarias que les deja la maestra, afectando así su aprovechamiento en la escuela y su comportamiento.

La maestra expresó que "se observan muchas dificultades, problemas en su aprendizaje, tanto en matemática, como en el español y resto de asignaturas que estudian." Según la maestra ha conversado algunas veces con las madres de los alumnos que presentan mayor problema en el aprendizaje, pero no han logrado una respuesta positiva. Entre otras razones, esa falta de apoyo pudiera interpretarse porque algunas de las madres entrevistadas no tienen un nivel académico, por tanto tampoco saben cómo ayudarles. Normalmente ponen de pretexto de que no tienen zapatos ni dinero, que están pequeños y que pueden estudiar el próximo año, y que además tienen que asumir los qué haceres de la casa, cuidar sus hermanos menores, cocinar, entre otros.

El Dr. Juan Bautista Arríen, (2007), explica al respecto que numerosos e importantes estudios han señalado la relación entre escolaridad de los padres --y de la madre en particular-- y factores que afectan la salud, la educación y el desarrollo de los hijos, lo que confirma la relación entre escolarización y los factores de desarrollo de un país. Una madre entrevistada expresa: "nuestra obligación es visitar con frecuencia a las maestras de nuestros hijos y tener confianza con ellos para mejorar la conducta y el aprendizaje de nuestros hijos, tratar de tener una estrecha relación entre padres y maestros" Esta expresión podría significar que las madres conocen muy bien cuál es su rol, pero aún así no lo asumen, si lograran asumir esa responsabilidad, sería otras oportunidades de aprendizaje para estas niñas y nińos.

\section{ESTRATEGIAS DE INTEGRACión DE PADRES Y MADRES A LA ESCUELA}

La maestra plantea que asume su responsabilidad apoyando en lo que puede a sus alumnos. Asigna tareas cada día en las diferentes asignaturas que imparten para que se ejerciten los alumnos en la casa; sin embargo, los padres de familia no cumplen con sus responsabilidades. Durante las observaciones en el aula de clase comprobamos que a pesar de todo la maestra ayuda a los alumnos que presentan mayor dificultad en la asimilación. Cuenta con el apoyo de otros alumnos que asimilan más rápidamente formándolos en grupo de estudio y ella apoya de forma individual a quien lo necesita. 
Parece ser que en la relación docente-madres se está lejos de lo que plantea la Dra. Ibarra, quien afirma que "debe existir una verdadera relación de comunicación" donde padres y maestros establezcan una vía abierta de diálogo e intercambio, de orientación, sobre la educación de los hijos, constructiva y exenta de tensiones por el papel que cada uno de ellos desempeña. La pregunta es: ¿Cómo lo puede lograr? Si no se da esa relación padres/madres-maestra, no será posible que se cumpla lo que plantea Pérez Gómez (1992), que considera necesario conocer las condiciones en las que se encuentra el individuo que aprende, es decir, su nivel de captación, de madurez y de cultura, entre otros. Es aquí donde entra en juego todo aquello que ha afectado la vida del o de la escolar, por lo que demanda de la integración de la familia en la tarea de educar y en el contexto escolar.

Es fundamental buscar estrategias como por ejemplo: visita domiciliar de parte de la docente o director para incidir en la reflexión sobre la importancia de su integración al qué hacer de la escuela y de las niñas/niños, realizar actividades conjuntas que motiven a las madres y padres a llegar a la escuela, construir de manera participativa con padres y madres de familia la agenda de las reuniones y divulgarla. Al respecto la Dra. Ibarra afirma que "la relación que se entabla entre familia y escuela es tan peculiar que sólo cabe situarla en el marco de la confianza, es la escuela, como parte de la familia, una prolongación suya, adquiriendo así su pleno sentido".

Es importante conocer y divulgar lo que se expresa en el Plan Nacional del Ministerio de Educación, (2000), "deben abordarse no sólo los factores a lo interno del centro educativo que afectan el aprovechamiento y provocan el abandono, sino también implementar estrategias que garanticen las transferencias e intervenciones necesarias en el ámbito familiar y comunal para que sea posible la realización de la inversión en la educación de los más pobres”. En la Región contamos con el Sistema Educativo Autonómico Regional (SEAR), contemplado en el II capítulo del Plan Nacional de Educación. Queremos destacar que los objetivos 7 y 8 del SEAR plantean la erradicación de la violencia intrafamiliar y contribuir al respeto a los derechos de niñas y niños.

Asimismo, en el principio No. 9 del Plan, deja claro que "Es deber y derecho de madres y padres de familia, instituciones, organizaciones y demás integrantes de la Sociedad Civil, participar activamente en la planificación, gestión y evaluación del proceso educativo, dentro de la realidad nacional, pluricultural y multiétnica”. Si bien la participación es un eje en el Plan Nacional de Educación y en el SEAR, ¿Quién vela por su implementación?

\section{CONCLUSIONES}

Conforme los resultados obtenidos y el análisis realizado llegamos a las siguientes conclusiones: 
Hay un alto índice de niñas y niños que viven en hogares de familias desintegradas, siendo estos afectados de manera negativa en el proceso de enseńanza aprendizaje, este tipo de familia no genera las bases que permitan tener un buen soporte emocional y estar preparados para afrontar los requerimientos que necesitan en dicho procesos que lo lleven a la niñez a empoderarse de esa realidad a partir del juego, la creación, la participación en el desempeño con autoconfianza en labores realmente significativas para sus edades y el desenvolviendo social y culturalmente pertinente.

La desintegración familiar afecta las relaciones sociales de niñas y niños; pero se pudo comprobar que los niveles de afectación son mayores en las niñas, esta relación de género tiene que ver culturalmente con los patrones educativos del entorno social de las madres, quienes delegan las responsabilidades en las niñas y no los niños; esta situación de rupturas familiares está directamente relacionada con círculos viciosos de repetición.

Esta crisis social que hemos analizado a través del estudio de caso, repercute en los adultos con la separación y ruptura familiar, afectando a su vez de modo negativo en apreciación de su entorno y la participación activa de estos padres y madres de familia en las actividades de la escuela es mínima, casi nula.

\section{GLOSARIO:}

Familia Desintegrada: Familia separada, en la que hay rupturas, divorcios, y niñez en abandono por un miembro de la pareja

Comunidad educativa: Llámese docentes, alumnos, y padres de familia

Neutralizar: Dejar sin efecto.

Aprendizaje: método para enseñar o aprender.

Mal comportamiento: indisciplina

Educación integral: que se imparten varias materias.

\section{LISTA DE REFERENCIAS}

Booth Amato (2001). The. Legacy of. Purents marital discord: consecuences for childrens marital psychology, 81:627-638.

Castillo R. Máximo (2000). Managua Nicaragua. Nuevo Diario página Webb: http://archivo el nuevodiario.com ni/2000/julio/03/julio /2000.

Ellsberg et all., (1996). INEC-MINS. Teoría general de los sistemas.

Edel N Ruben. (2004). El concepto de enseñanza-aprendizaje.Veracruz.ver C.P.México 
García Vega (1999). Evaluación Pedagógica. En pág. Web: http. www / psicopedagogía. com

Gómez Angel y Nuñez Rogal L. (2003). Matrimonio y familia. Sitio Webb. www- ni.la prensa.com.n/archico ../2003/junio/2/03/revista - $200330623-07 \mathrm{html}-15 \mathrm{k}$.

Dra. Ibarra Mustelear (2003). Educar en la escuela, educar en familia. Realidad a utopía. Julio 2-2003.

Marqueurdt (2006). Los efectos del divorcio en los hijos. Center for marriage and families. Parte del instituto for american vallues; con la sede en NuevaYork.

Martínez Ana et al (2005). El papel de las relaciones familiares en el rendimiento escolar y el bienestar psicológico de los adolescentes. Publicado en Psicoteca

Ministerio de Educación, Cultura y Deportes. Plan Nacional de Educación, 2000. Ministerio de Educación, Cultura y Deportes. Sistema Educativo Autonómico Regional.

Navarrete C. Alfonso (2000). Causas y efectos de los flagelos sociales que afectan a la niñez y la adolescencia de la Costa Atlántica de Nicaragua. FADCANIC. Pág. 3 -9

Navarrete C. Alfonso (2000). El entorno familiar de la niñez y la adolescencia en las Regiones Autónomas del Caribe Nicaragüense al 31 de agosto del 2000. FADCANIC en la página Web http://www.fadcanic.

Navarrete Alfonso (2000). Entorno familiar de la niñez y adolescencia. FADCANIC.

Pérez Gómez (1992). La función y formación del profesor, enseñanza para la comprensión y transformar la enseñanza. Madrid. Edición Morata.

Sola M.J (1989). Pedagogía en pildoras. Trillas, México.

Suárez Rodolfo (2005). El Mañana de nuevo. 